\title{
ANÁLISIS COMPARATIVO DE LA COMPETITIVIDAD DE LAS ECONOMÍAS DEL PERÚ Y CHILE DESDE UN ENFOQUE GLOBAL*
}

\author{
COMPARATIVE ANALYSIS OF COMPETITIVENESS ON THE \\ PERUVIAN AND CHILEAN ECONOMIES FROM A GLOBAL VIEW
}

Jesús C. Peña-Vinces ${ }^{1}$

\section{RESUMEN}

Las economías pequeñas como la peruana y la chilena se encuentran inmersas en la arena global de las economías emergentes por lo que evaluarlas desde un punto de vista puramente local (homed based, Porter, 1990) sería un enfoque bastante limitado y poco útil; por ello el diamante nacional de Porter (1990) resulte a todas luces insuficiente para este propósito (Moon, Rugman y Verbeke, 1998: 135). Este artículo analiza estas economías desde un enfoque global que incluye tanto el mercado local como el extranjero, es decir, desde la perspectiva del doble diamante de la competitividad internacional propuesto por Moon, Rugman y Verbeke (1998) y Moon y Lee (2004). Para la elaboración del doble diamante se utilizó información procedente del Banco Mundial, el Fondo Monetario Internacional, el Foro Económico Mundial, el Banco Interamericano de Desarrollo y otros. Los análisis empíricos muestran que Chile es más competitivo globalmente, mientras que el Perú lo es más localmente. En resumen, el resultado implica que Chile es más atractivo que el Perú para la inversión directa extranjera.

Palabras claves: doble diamante, competitividad global, economías emergentes, pilares de competitividad, competitividad de Chile y el Perú.

\begin{abstract}
Small economies, such as the Peruvian and Chilean, are immersed in the global arena of emergent economies, so evaluating them from a home based point of view (Porter, 1990) would be limited and of little use. This fact turns Porter's national diamond framework insufficient for that purpose (Moon, Rugman and Verbeke, 1998). This paper analyzes these economies from a global view that would include local as well as foreign markets; in other words, it applies the International Competitiveness Double Diamond approach proposed by Moon, Rugman \& Verbeke (1998), and Moon \& Lee (2004). Information from the World Bank, the International Monetary Fund, the World Economic Forum, the Inter-American Development Bank and other sources was gathered to draw up the double diamond. The empirical analyses show that Chile is more competitive globally, while Peru is locally. To sum up, the results imply that Chile is more attractive to direct foreign investment than Peru.
\end{abstract}

Keywords: Double diamond, global competitiveness, emergent economies, competitive pillars, competitiveness of Chile and Peru.

* El autor desea expresar su especial agradecimiento al árbitro anónimo de la Universidad ESAN por sus valiosos comentarios que han sido de mucha utilidad para mejorar el contenido de este artículo.

1. Universidad de Sevilla (España). Ph. D. (C) in Economics and Business, Universidad de Sevilla (España).<jesuspvinces@us.es>. 


\section{INTRODUCCIÓN Y MARCO TEÓRICO}

El comercio internacional, que ha permitido y sigue permitiendo el desarrollo económico de muchos países, siempre ha sido estudiado desde la perspectiva de las teorías clásicas del comercio internacional como:

1) El mercantilismo de David Hume (1752). Quien afirmaba que el comercio internacional era un juego de estrategia entre naciones ganadoras y perdedoras. El principal objetivo ambicionado era una balanza comercial positiva; para ello abogaba por la intervención directa del gobierno en el comercio internacional estimulando las exportaciones y restringiendo las importaciones.

2) La teoría de la ventaja absoluta de Adam Smith (1776), quien, en La naturaleza y las causas de la riqueza de las naciones, afirmaba que si no existieran barreras en el comercio internacional cada país se especializaría en aquellos productos y servicios en los que presentara una ventaja absoluta con respecto de los demás, por tanto, existiría una especialización de cada uno de forma que los recursos se concentrarían en los sectores más eficientes aumentando en consecuencia las exportaciones de estos productos. En definitiva, según Smith, el comercio no era una estrategia de ganadores y perdedores, sino una fórmula que garantizaba mayor bienestar y riqueza para sus participantes $y$, por consiguiente, debía eliminarse toda política que dificultase el libre comercio (la interferencia gubernamental debería ser mínima).

3) La teoría de la ventaja comparativa de David Ricardo (1817) establecía que cada país se especializaría en aquellos bienes en los que fuese más eficiente en comparación con otros. Es decir, que un país debería exportar aquellos bienes y servicios que pudiese producir a un costo menor e importar aquellos que otro país produjese a menor costo; en otras palabras, se trataba de que ambas naciones se beneficiasen como producto del intercambio comercial.

4) La teoría de la proporción de los factores, la cual parte de que los modelos anteriores consideran al trabajo como factor principal de la eficiencia de la producción de bienes y servicios de un país, pero la participación de otros factores como el capital y la tecnología comenzó a tener cada vez un mayor papel. Hecksher (1919) estableció que la ventaja comparativa de un país venía proporcionada por la abundancia relativa de recursos y la intensidad de su utilización en tecnología. Es decir, los países con mano de obra barata debían exportar productos intensivos en mano de obra, mientras que aquellos que tenían un elevado nivel de desarrollo tecnológico tenderían a exportar bienes con dicho factor. Para contrastar empíricamente el teorema planteado por Hecksher (1919), y reformulado por Bertil Ohlin (1933), surgió la paradoja de Wassily Leontief (1953) que consiste en el hecho de que los Estados Unidos exportaba muchos bienes intensivos en mano de obra e importaba muchos bienes intensivos en capital. La explicación de este fenómeno se encuentra en la calidad de la mano de obra, factor que no fue suficientemente considerado por esta teoría.

Todas estas teorías se centraban en el comercio internacional como principal exponente de la competitividad internacional de las naciones. Sin embargo, recién en la década de 1960 aparecen otros enfoques que consideren a la Inversión Directa Extranjera (IDE). Hymer (1960) fue el primer autor en relacionar el concepto de competitividad nacional e IDE. En su trabajo consideró explícitamente las diferencias existentes en cuanto a las capacidades de unos países y otros.

5) La teoría del ciclo de vida fue planteada por Raymond Vernon (1966), quien afirmó que muchos de los productos fabricados pasan por un ciclo de cuatro etapas sucesivas: introducción, crecimiento, madurez y declive. La hipótesis básica del ciclo de vida del producto empieza con el supuesto de que el estímulo a la innovación procede normalmente de alguna amenaza u oportunidad en el mercado. Es decir, las empresas tienden a ser estimuladas por las necesidades y las oportunidades del mercado. Estas necesidades cumplen dos funciones importantes en esta teoría: no solo son fuente de estímulo para la empresa innovadora sino también determinan el lugar preferido para la producción. 
Porter (1990), con la publicación de su famosa obra La ventaja competitiva de las naciones, resume ampliamente las teorías descritas hasta aquí que habían analizado el concepto de competitividad desde un punto de vista puramente macroeconómico. Este autor va más allá de este enfoque e incorpora el análisis microeconómico con la propuesta de un modelo de competitividad denominado diamante, cuya finalidad era servir de orientación a los empresarios y a los políticos acerca de por qué unas naciones son más competitivas que otras; es decir, muestran un mejor escenario económico (Cho \& Moon, 1998). Sus estudios se sustentaban en las siguientes variables: condiciones de los factores, condiciones de la demanda, sectores conexos y de apoyo, y estrategia, estructura y rivalidad de las empresas. Además, incluyó dos variables auxiliares: el papel que desempeñan los gobiernos locales y los factores o hechos casuales (el azar). Todos ellos integran el sistema o los determinantes de la ventaja nacional al cual Porter denominó "diamante".

El trabajo de Porter tampoco queda exento de limitaciones $y$, en respuesta a ellas y como alternativa, surge el modelo del doble diamante de Moon, Rugman y Verbeke (1998, p. 138) para evaluar la competitividad internacional o los escenarios económicos de los países.

Rugman y D'Cruz (1993, p. 17) afirmaban que el diamante de la ventaja competitiva de las naciones propuesto por Porter (1990) mostraba una serie de limitaciones cuando se trataba de analizar cualquier economía pequeña. En respuesta a esas limitaciones aparece el modelo del doble diamante de la competitividad internacional (Figura 1) propuesto por los investigadores Moon, Rugman y Verbeke (1998, p. 138). Ellos afirmaban que cuando Porter (1991) fue consultado por los gobiernos de Canadá y Nueva Zelanda su modelo del diamante nacional no pudo explicar el éxito de los sectores internacionales porque, argumentaban, que su enfoque se centraba básicamente en el mercado local (Moon, Rugman, \& Verbeke, 1998, p.136). Sin embargo, hoy en día el éxito de las economías en escala mundial se debe a sus empresas que operan tanto local como internacionalmente (Dunning \& Lundan, 1998, p. 131; Moon \& Lee, 2004, p. 20). Además, el éxito de estas últimas depende sobre todo de actividades provenientes del extranjero, sea mediante exportaciones directas o IDE (inward/outward); Japón es una clara muestra de ello (Chen \& Lin, 2006; Jin \& Moon, 2006).

El concepto de competitividad global ha sido definido como un modelo de evaluación de los escenarios económicos internacionales (Choo, 1994, p. 13; Cho \& Moon, 2000, p. 187; Porter, Delgado, Ketels, \& Stern, 2008). Tal es así que existen dos instituciones reconocidas como el International Institute for Management and Development (IMD) y el World Economic Forum (WEF) que también evalúan la competitividad de los países a partir de una metodología propia. Sin embargo, esta no será utilizada en esta investigación porque, como afirma Lora (2005, p. 10), la evaluación realizada por estas instituciones muestra una serie de limitaciones pues sus análisis se orientan a los países más ricos, y lo que aquí se estudiará son dos países que aún no tienen una elevada tasa de industrialización. De acuerdo con el modelo de desarrollo económico flying geese (Chen \& Lin, 2006; Kasahara, 2004; Kojima, 2003), estos países se encontrarían en la etapa tercera del modelo, es decir, son países en vías de desarrollo, también llamados emergentes, que exportan bienes de consumo a los países desarrollados (orientación exportadora) en los cuales la producción local comienza a alcanzar economías de escala y, simultáneamente, disminuye la importación de maquinaria que es sustituida en parte por la producción local. De allí que en esta investigación se opte por utilizar una herramienta más sencilla y menos compleja que los modelos tradicionales del IMD y el WEF, como el modelo del doble diamante.

A pesar del permanente debate suscitado por el uso de los términos competitividad de un país (Cho \& Moon, 2000), competitividad de los sectores industriales (Porter, 1990, 1998) y de la empresa (Dunning \& Lundan, 1998; Krugman, 1997; Moon \& Lee, 2004) parece que por fin hay acuerdo entre los diversos investigadores, dada la complejidad y las connotaciones que encierra el uso de esta palabra, por lo que la comunidad académica ha aceptado que este puede ser usado en los tres niveles: país, sector y empresa (Cho, Moon, \& Kim, 2007, 2009; Porter, 2007; Porter et ál., 2008; Sala-I-Martin, Blanke, Drzeniek Hanouz, Geiger, Mia, \& Paua, 2008). 
El estudio de la competitividad de un país no es solamente un ejercicio de análisis económico sin trascendencia social, sino todo lo contrario; busca identificar vías (factores) para que las empresas nacionales sean más competitivas y que, a través de la generación de empleos mejor remunerados y estables, contribuyan a la elevación real de los niveles de bienestar (Solleiro \& Castañón, 1995; Sala-I-Martin et ál., 2008). Puesto que se afirma que actualmente el motor que mueve la economía de un país son las empresas, sean de propiedad estatal o privada, ya que cuando mejora la situación de estas mejora también la economía del país en todo nivel.

La situación actual de la economía mundial y los negocios se caracteriza por la globalización de los mercados, el creciente uso de las tecnologías de la información y la gestión del conocimiento (knowledge management) y por un entorno dominado por el cambio continuo, rápido e incierto. Estos tres impulsores de la economía y los negocios en el mundo han dado lugar a un nuevo panorama competitivo que es el de la hipercompetencia global en los mercados internacionales y locales (Villarreal \& Villarreal, 2002). Por esta razón, los países han tenido que abrir sus economías para participar en la economía mundial y los mercados internacionales al tiempo que defienden sus mercados locales, lo que ha creado un nuevo paradigma de competitividad: la competitividad sistémica en la cual se establece la relación entre empresa, industria, gobierno y país (Villarreal \& Villarreal, 2002). Esta nueva situación también se caracteriza por que la competencia en el mercado es cooperativa por la vía de alianzas estratégicas entre competidores, clientes y proveedores, gobiernos y universidades (D'Cruz \& Rugman, 1993) y busca la cooperación y la interacción entre la empresa y el mercado.

Así, el objeto de estudio de la competitividad internacional de las naciones ha pasado de las ventajas competitivas que se centraban solo en los recursos tangibles a concentrarse en las ventajas competitivas intangibles como la innovación y la gestión del conocimiento apoyada básicamente en las personas que generan este nuevo capital escaso de las naciones (knowledge based view).
EN DEFINITIVA, ESTE ARTíCULO busca analizar la competitividad global de las economías del Perú y Chile utilizando como herramienta el modelo del doble diamante de la competitividad global. En términos figurados, se trata de hacer una radiografía de estas economías con la finalidad de explicar por qué Chile hoy en día es visto como una de las economías líderes de Hispanoamérica y, por tanto, más atractiva para las IDE respecto del Perú.

Es importante mencionar que el modelo del doble diamante no es un modelo de desarrollo económico propiamente dicho, si no, por el contrario, una herramienta de análisis que permite situar de manera sencilla a políticos e investigadores sobre el escenario económico que muestra un país respecto de otro. Este modelo ha sido usado por las grandes economías del Sureste Asiático, aquellas de mayor crecimiento económico en los últimos tiempos (Jin \& Moon, 2006; Cho et ál., 2009).

Este trabajo se inicia con el planteamiento de la variable dependiente, en seguida se analizan las variables independientes $y$, antes de formular las conclusiones y las implicaciones para la gestión, se hace una lectura general de los modelos de doble diamante en Chile y el Perú, como producto del análisis matemático realizado para cada variable, tanto en el contexto local como en el contexto internacional.

\section{DESARROLLOY APLICACIONES DEL MODELO DEL DOBLE DIAMANTE}

El doble diamante generalizado es un desarrollo del "doble diamante" introducido por Rugman y D'Cruz (1993, p. 34), cuyo propósito consistía en hacer funcionar el modelo del doble diamante (Figura 1) para analizar cualquier economía pequeña. Este modelo fue desarrollado por Moon, Rugman y Verbeke (1995) para subsanar algunas debilidades del modelo del diamante de Porter (1990) mediante la incorporación de las actividades de las multinacionales y el gobierno dentro del modelo, y no como parámetros exógenos.

El doble diamante está compuesto básicamente por las mismas variables planteadas por Porter (1990), 
es decir, condición de la demanda, condición de los factores, sectores conexos y de apoyo, y estrategia, estructura y rivalidad; pero con una diferencia significativa en su aplicación pues se analizan en un contexto local y en otro externo y la suma de los dos mercados constituye el denominado doble diamante (Figura1). te, de sus ciudadanos. No obstante, se añaden también otras variables que tienen mucho interés para este análisis, tal como indican Moon y Lee (2004, pp. 8-15).

El Cuadro 1 muestra un listado de factores que permiten realizar un análisis comparativo de los escena-

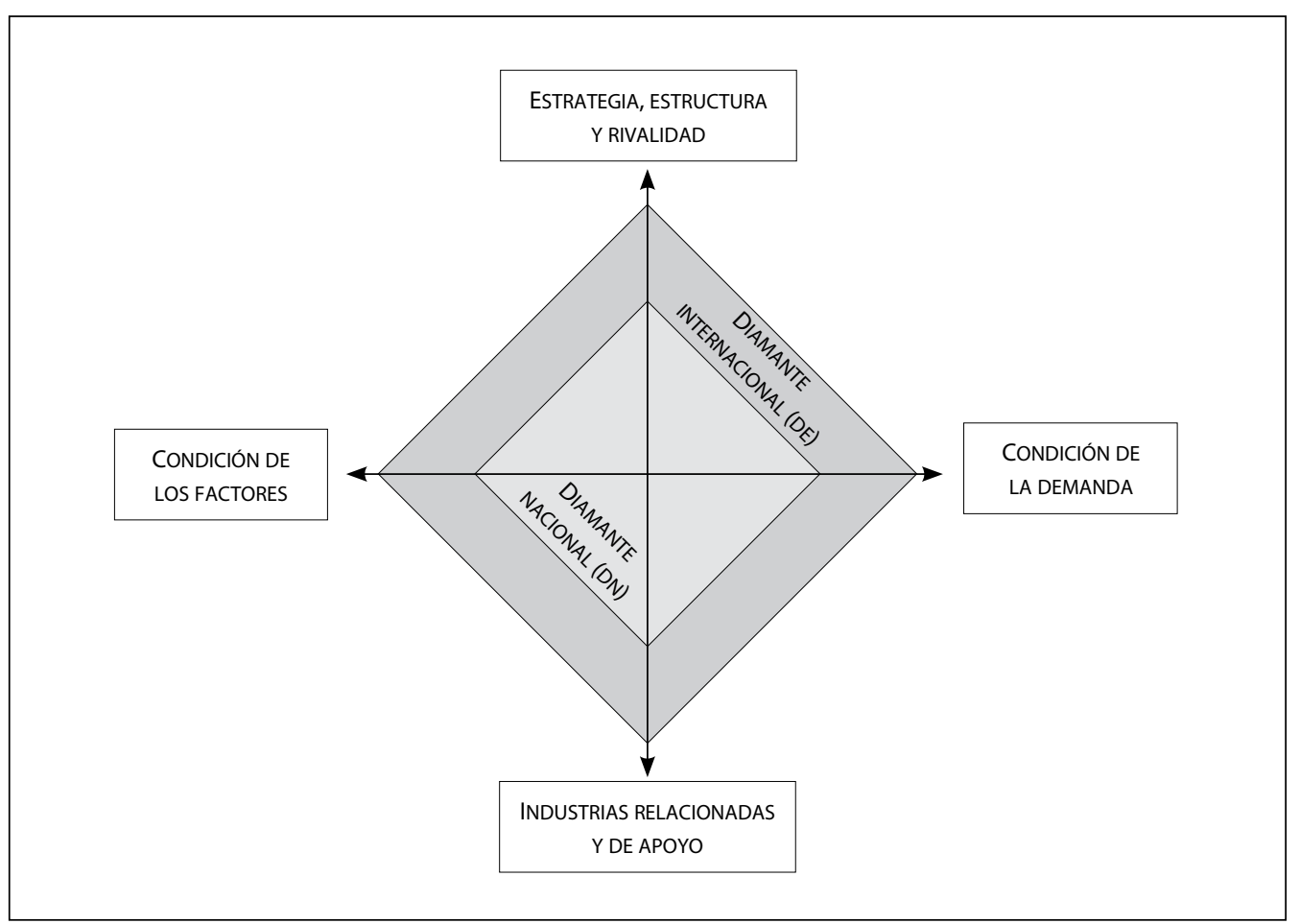

Figura 1. El doble diamante generalizado (nacional e internacional)

Fuente: Moon, Rugman y Verbeke, 1998: 138.

A continuación se desarrolla cada uno de estos aspectos en las economías de los países considerados en esta investigación: Chile y el Perú.

Para el análisis de la variable dependiente se utiliza el PBI en el sentido de Porter (1998, p. 160), quien argumentaba que la competitividad nacional de un país es sinónimo de la productividad, por tanto, esta variable refleja muy bien la capacidad agregada que tienen los países para generar riqueza para sus propias economías (Porter et ál., 2008). En seguida se incorporan tres variables que pertenecen básicamente a los sectores productivos (empresas) al considerar que son las principales generadoras de la riqueza de los países y, por consiguien- rios económicos peruano y chileno. A simple vista se puede observar que el $\mathrm{PBI}$ de Chile es mayor. Como afirmaban Del Sol y Kogan (2007, p. 901), esto se debe a que Chile comenzó la liberalización de su economía en la década de 1970, mientras que el Perú lo hizo dos décadas después (Del Sol \& Kogan, 2007, p. 905), quizá sea esta una de las razones de la diferencia. Si bien es cierto que actualmente el Perú tiene una tasa de crecimiento mayor del PBI, es probable que esto se deba a las nuevas reformas impulsadas por el gobierno actual en materia económica internacional.

En lo concerniente al uso de energía, variable que refleja la rapidez con la cual se industrializa un país, 
Cuadro 1. Factores que Integran la Variable Dependiente

\begin{tabular}{lcc}
\hline \multicolumn{1}{c}{ Variables } & Perú & Chile \\
\hline Variables del país & $\mathbf{2 0 0 6 - 2 0 0 7}$ & $\mathbf{2 0 0 6 - 2 0 0 7}$ \\
PBI (millones de dólares) & 99.81 & 155.17 \\
Tasa de crecimiento del PBI (\%) & 8.3 & 4.7 \\
Uso de la energía (kilogramos de petróleo per cápita) & 495.67 & $1,769.67$ \\
Ingreso nacional bruto (INB) per cápita, método Atlas (US \$) & 7,240 & 12,590 \\
\hline Variables de los sectores industriales & 2006 & 2006 \\
Rentabilidad de recursos propios (ROE) & 14.00 & 20.85 \\
Rentabilidad de los activos (ROA) & 8.86 & 15.16 \\
Impuestos aplicados a las empresas (\%) & 30.96 & 13.97 \\
\hline
\end{tabular}

Fuente: Banco Mundial (BM); Banco Interamericano de Desarrollo (BID); Parker (2006a y b: 77).

Chile tiene un gasto mayor respecto del Perú: una tasa diferencial de $28 \%\left(495.67 / 18,769.67^{*} 100\right)$, en este sentido se afirma que el sector industrial crece con mayor rapidez en Chile. Por consiguiente, esa riqueza se ve expresada en la renta real de sus ciudadanos (INB per cápita) que es en Chile $58 \%$ mayor que en el Perú $(7,240 / 12,590 * 100)$, aunque es importante aclarar que ambos países pertenecen geográficamente a la misma región económica.

Si nos referimos a la rentabilidad de los sectores industriales, vemos que en Chile es más rentable invertir porque cuenta con una mayor capacidad para atraer IDE (ROE: 20.85\%; ROA: 15.16\%), además, el nivel de impuestos o la presión fiscal es menor en Chile en $45 \%$, lo que constituye una plataforma de despegue si se busca que los sectores industriales de un país sean competitivos internacionalmente (Galán, GonzálezBenito, \& Zúñiga-Vincente, 2007, p. 986).

El bajo nivel del Perú en este factor se debe a dos elementos: en primer lugar, según las investigaciones realizadas por Garrido-Lecca (2008), a la concentración bancaria que muestra el país (un mercado financiero controlado por cuatro grandes bancos: Banco de Crédito, BBVA, ScotiaBank e Interbank), y, por consiguiente, los costes del dinero son más elevados que en cualquier otra parte de la región y además aumenta la dificultad de conseguir créditos, todo lo cual disminuye la rentabilidad de las empresas. El segundo se refiere al nivel de los impuestos, pues el Perú inició sus reformas fiscales para atraer IDE en la década de 1990, tal como demostraron Del Sol y Kogan (2007, p. 905), mientras que Chile ya las había iniciado aproximadamente 16 años atrás.

De acuerdo con Moon, Rugman y Verbeke (1998, p. 140), las variables que aquí se plantean para medir la variable dependiente de un modo descriptivo sirven para sustentar que Chile muestra un mejor escenario económico que el Perú en lo concerniente a esta variable.

\section{PILARES DEL MODELO DEL DOBLE DIAMANTE DE LA COMPETITIVIDAD INTERNACIONAL}

Los pilares de este modelo, es decir las variables independientes, se señalan a continuación: condición de los factores, condiciones de la demanda, industrias relacionadas y de apoyo, y estrategia, estructura y rivalidad.

Existe aún un gran debate entre diversos investigadores que se refleja en las obras de Jin y Moon (2006), Moon, Rugman y Verbeke (1995), Rugman y D'Cruz (1993), entre otros, acerca de qué factores podrían o no ser incorporadas dentro de las variables del modelo (Figura 1). Luego de una exhaustiva revisión de la literatura sobre los factores incluidos por estos autores, se han incorporan algunos más como los propuestos por Dunning y Lundan (1998, p. 119) y Moon y Lee (2004, pp. 8-15), lo que ha dado como resultado los factores que se incluyen en este modelo en los Cuadros 2, 3, 4 y 5. 


\section{Condición de los factores}

Para el análisis de esta variable se emplean aquellos aspectos considerados por Moon, Rugman y Verbeke (1998, p. 141), además de dos planteados por Moon y Lee (2004, p. 6), como se aprecia en el Cuadro 2.

La disponibilidad de mano obra calificada es una medida que intenta reflejar el nivel de avance de un país, es decir, si funciona de acuerdo con la nueva economía: knowledge based economy o economía del conocimiento (Lowe, 2003); mientras que la disponibilidad de capital se mide por la facilidad con la que las empresas pueden acceder a las fuentes de financiación (Porter, 1990).

El porcentaje total de áreas o terrenos cultivables sobre la cantidad de terrenos que tiene un país mide la disponibilidad de recursos físicos con los que cuentan las empresas de algunos sectores industriales que luego sirven de materia prima para la transformación en productos finales con un alto valor añadido (Cho \& Moon, 2000; Porter, 1990). Por ejemplo, algodón en camisas o mangos en jugo.

Asimismo, la dimensión de las áreas forestales indica el grado en que un país explota sus recursos naturales teniendo en cuenta la ecología. Puesto que, sea por moda o porque realmente les interesa, todos los países se han unido al boom del green management o gestión verde. Para el caso de las variables de este factor de análisis se consideran en el aspecto internacional: la capacidad que tienen empresas y gobiernos para captar IDE (Moon, Rugman \& Verbeke, 1998, p. 142).

Por otro lado, el valor agregado de la industria mide el valor real que las industrias añaden a la productividad de un país, es decir, qué porcentaje del PBI se explica o se debe a la contribución de los sectores industriales.

Las restricciones legales a la IDE expresan las facilidades que tienen los inversionistas para desplazar sus IDE, como FDI o inward/outward (WEF, 2008).

El último factor de análisis dentro de esta variable se refiere a la existencia de las barreras que deben atravesar las empresas para internacionalizarse y convertirse en empresas más competitivas globalmente.

Es preciso aclarar que la disponibilidad de mano de obra calificada se refiere a la posición que otorga el WEF a Chile y el Perú entre 131 economías, aquella economía que tiene una posición más cercana a la unidad goza de una mejor disposición de mano de obra calificada. Es importante tener presente este criterio de análisis, pues cuando se analizan las variables con información proporcionada por el WEF esas variables mantendrán la misma metodología con el fin de dar robustez al modelo (los resultados de este análisis se presentan en el Cuadro 7).

Cuadro 2. Elementos que Forman la Variable: Condición de los Factores

\begin{tabular}{lcc}
\hline \multicolumn{1}{c}{ Elementos } & Perú & Chile \\
\hline Condición de los factores locales & & \\
$\quad$ Disponibilidad de mano de obra calificada: ránking de competitividad del WEF (PRW) & 78 & 34 \\
Restricción de los flujos de capital (PRW) & 33 & 64 \\
Terrenos cultivables (\% del total de terrenos) & 16.0 & 20.4 \\
$\quad$ Áreas forestales (cantidad de km² en 2005) & 687.4 & 161.2 \\
\hline Condición de los factores extranjeros & & \\
$\quad$ IDE en millones de dólares en 2006 & 3,467 & 7,952 \\
Valor agregado de la industria como porcentaje del PBI en 2006 & 38 & 48 \\
Restricciones legales a la IDE (PRW) & 44 & 16 \\
Barreras del comercio internacional (PRW) & 74 & 11 \\
\hline
\end{tabular}

Fuente: BM; WEF. 


\section{Condiciones de la demanda}

La tasa de crecimiento de los mercados locales es más importante para la ventaja competitiva que el tamaño absoluto del mercado (Moon, Rugman \& Verbeke, 1998, p.142), además, el nivel de complejidad que han alcanzado los clientes es relevante porque las empresas se acostumbran a distribuir productos y servicios en mercados de estas características; en consecuencia, se encuentran más y mejor preparadas para competir en el mercado extranjero (Casillas, 2001, p. 64; Porter, 1990, p. 129). Lo que significa que este nivel evalúa la capacidad de las industrias para satisfacer las necesidades del mercado local con marcas y diseños creativos, esto les permite estar preparadas para competir en el terreno internacional (Jin \& Moon, 2006, p. 198).

\section{Industrias relacionadas y de apoyo}

Las industrias relacionadas son aquellas que la empresa necesita para coordinar actividades de apoyo y son un complemento de su actividad empresarial. Por ejemplo, los bancos, los distintos proveedores, la transferencia de tecnología, el apoyo de los gobiernos con infraestructura, políticas fiscales, acceso a las fuentes de financiamiento, etcétera (Porter 1998, p. 176). Esta es una de las razones de la elección de los factores de esta variable en el plano local. En economías pequeñas como la chilena y la peruana, la infraestructura local desempeña un papel decisivo para la competitividad local e internacional de sus empresas; mientras que en economías más avanzadas este factor puede carecer de importancia ${ }^{1}$. Otro aspecto que es considerado re-

Cuadro 3. Elementos que Forman la Variable: Condiciones de la Demanda

\begin{tabular}{lcc}
\hline \multicolumn{1}{c}{ Elementos } & Perú & Chile \\
\hline Condición de la demanda local & & \\
$\quad$ Tasa de crecimiento anual de la población (\%) & 1.1 & 1.0 \\
Importación de bienes y servicios como porcentaje del PBI & 19 & 34 \\
$\quad$ Nivel de complejidad del mercado local (PRW) & 64 & 29 \\
\hline Condición de la demanda extranjera & & \\
$\quad$ Exportación de bienes y servicios como porcentaje del PBI & 27 & 48 \\
Crecimiento del mercado extranjero (PRW) & 58 & 43 \\
\hline
\end{tabular}

Fuente: BM; Fondo Monetario Internacional (FMI); WEF.

Las importaciones de bienes y servicios como porcentaje del PBI cumplen un papel muy importante dentro de los análisis de esta variable puesto que con este factor se pretende evaluar la capacidad que tienen las empresas nacionales para defender su demanda local de competidores extranjeros (Porter, 1998). Mientras que el factor referido a las exportaciones de bienes y servicios refleja la capacidad de las industrias nacionales para satisfacer la demanda de los mercados extranjeros (Jin \& Moon, 2006).

Asimismo, el índice de crecimiento del mercado permite que las industrias de un país diseñen sus estrategias de expansión internacional en función de los niveles de crecimiento de los mercados extranjeros. levante dentro de este análisis se refiere a la capacidad que tienen las industrias para utilizar su propia tecnología para competir en el mercado extranjero (PeñaVinces, 2008).

1 Es importante aclarar que en el plano internacional son las empresas las que salen a competir por un determinado mercado (Estados Unidos, la Unión Europea, Asia) y no el país en sí; sin embargo, se destaca la importancia que tienen los países en la competitividad global, ya que en economías pequeñas como las de Chile y el Perú las empresas no podrían competir internacionalmente sin la ayuda de su país (recursos físicos, humanos, técnicos, políticas económicas y fiscales, etcétera) y del sector (tecnología y know-how) al que pertenecen. Por tanto, la competitividad global es sistémica pues se establece la relación entre país, sector y empresas. 
En la actualidad, los clientes extranjeros exigen a sus proveedores ubicados en mercados locales la entrega de algunos productos en el menor tiempo posible y de manera oportuna (just in time delivery) dada la temporalidad de ciertos productos, de allí la importancia de que los países cuenten con un buen sistema de transporte aéreo. Desde luego que la entrega oportuna de estos productos no solo es importante para los clientes afincados en el exterior. Por otro lado, existen productos que son requeridos en mayor volumen, por eso es crucial que los países posean un buen sistema de transporte marítimo. Se ha mencionado que la facilidad de financiación era básica para las industrias, pero no únicamente esto es crucial sino también lo es el volumen de financiación del que disponen las industrias locales; pues para hacer frente a un alto volumen de demanda extranjera necesitan cantidades mayores de liquidez para que las operaciones en el extranjero resulten rentables. Por ello se debe incluir este factor de análisis dentro de la variable del modelo del doble diamante. tos relacionados, por un lado, con el sector de la empresa y, por otro, con los objetivos y las estrategias que las empresas pretendan alcanzar. En ese sentido, Porter (1990) desagregaba esta variable en dos segmentos: los objetivos de la empresa y la rivalidad externa.

\section{Los objetivos de la empresa}

Las metas y los objetivos que buscan las empresas dependerán mucho de la nación de origen de estas, pues estos elementos están influenciados por la estructura del país; la cual está sujeta a la intervención de los clusters de determinadas regiones y los roles que ejercen ciertos grupos de interés que difieren en cada país y afectan las estrategias de las empresas. Esto significa que los recursos y las capacidades de las empresas $(\mathrm{RBV})^{2}$, se ven afectados por el entorno nacional (Grant, 1991). En ese sentido, Porter (1998, p. 107) reafirma la idea de que un entorno favorable del país local (entorno nacional) se convierte en plataforma de despegue para las empresas que van a competir en

Cuadro 4. Elementos que Forman la Variable: Industrias Relacionadas y de Apoyo

\begin{tabular}{lcc}
\hline \multicolumn{1}{c}{ Elementos } & Perú & Chile \\
\hline Industrias relacionadas y de apoyo del mercado local & & \\
Carreteras pavimentadas como porcentaje del total de carreteras en 2005 & 13 & 18 \\
Disponibilidad de proveedores locales (PRW) & 24 & 46 \\
Capacidad de absorción empresarial de tecnología (PRW) & 92 & 38 \\
\hline Industrias relacionadas y de apoyo del mercado extranjero & & \\
Calidad de la infraestructura de transporte aéreo (PRW) & 98 & 31 \\
Calidad de la infraestructura de transporte marítimo (PRW) & 122 & 34 \\
Disponibilidad de capital (PRW) & 19 & 40 \\
\hline
\end{tabular}

Fuente: BM; WEF.

En definitiva, entendiendo que las industrias locales por sí solas no pueden competir en determinados mercados (Jin \& Moon, 2006, p. 206; Moon, Rugman, \& Verbeke, 1998, p. 142) se deben considerar los factores de análisis que se presentan en el Cuadro 4.

\section{Estrategia, estructura y rivalidad}

Según Moon, Rugman y Verbeke (1995), la última variable de análisis del doble diamante que condiciona la ventaja competitiva de los países se refiere a los aspec- el plano internacional. También resalta la importancia de la presencia de los clusters locales, pues afirma que estos aportan un amplio conocimiento del sector, ayudan a las empresas a operar en terrenos internacionales poco conocidos y favorecen la internacionalización de las empresas (1998, p. 179). En la misma línea, BelsoMartínez (2006, pp. 212-213) afirmaba que un elemento

2 (RBV) resource based view, la capacidad que tiene la empresa para transformar sus recursos y capacidades internas en fuente de ventaja competitiva (ver Acedo, Barroso y Galán, 2006). 
crucial dentro de los clusters locales era establecer redes locales e internacionales porque muchas veces existen empresas que no podrían acceder por sí solas a los mercados extranjeros.

\section{La rivalidad interna}

Una fuerte competencia interna constituye un gran aliciente para la preparación de las empresas que van a competir o están compitiendo internacionalmente (Salas, 1999), por ello en el país donde el mercado es más atractivo comercialmente se encuentran importantes rivales locales que hacen que las empresas se preocupen por innovar, diferenciar su producción, mejorar continuamente y ofrecer productos cada vez mejores que otorguen mayor valor que sus competidores (Jin \& Moon, 2006). Las empresas acostumbradas a competir en un entorno difícil y cambiante están preparadas para competir internacionalmente (Casillas, 2001).

Moon, Rugman y Verbeke (1995) utilizaban como parámetro algunos de los factores que se describen en el Cuadro 5. Sin embargo, en este análisis, de acuerdo con Moon y Lee (2004), se han incorporado las variables planteadas por estos investigadores, puesto que se considera que así esta variable permitirá otorgar mayor poder predictivo al modelo de evaluación de la competitividad.

Entre los factores que destacan como parámetros de medida de esta variable está el tiempo que tarda un empresario en un país determinado para abrir una empre- sa o negocio, lo que refleja el nivel de burocratización y el nivel del desarrollo económico industrial (Porter et ál., 2008). Igualmente, el uso de tecnología de la información permite que las empresas ofrezcan sus productos en cualquier parte del mundo, en palabras de Drucker: “... el uso de las tecnologías de la información no sólo ha permitido acortar distancias entre comprador y vendedor, sino todo lo contrario, ha permitido eliminar las distancias geográficas..." (2003, p. 56). Por esta razón, se emplea como parámetro el uso de Internet por cada cien habitantes, pues refleja el empleo de las nuevas tecnologías en los diferentes países. Por otro lado, las exportaciones de alta tecnología cumplen un papel vital para la evaluación de este aspecto del área del doble diamante en su faceta internacional, porque miden la capacidad de las industrias o las empresas de un país para rivalizar con competidores extranjeros (Jin \& Moon, 2006) al ofrecer productos altamente diferenciados realizados mediante tecnología local (Peña-Vinces, 2008). Además, el control internacional de la distribución mide el uso eficiente de las estrategias de las industrias de un país para ganar una porción o una participación en los mercados globales; es decir, pretende evaluar los modos de entrada de las empresas a los mercados extranjeros, mediante estrategias de joint venture, licencias, franquicias, exportaciones directas, etcétera (para un mayor detalle véase Casillas, 2001, pp. 151-173).

Una vez establecido el marco teórico, se procederá a realizar el análisis matemático para cada variable de análisis del modelo con el fin de determinar el diseño del doble diamante para las economías de Chile y el Perú.

Cuadro 5. Elementos que Forman Ia Variable: Estrategia, Estructura y Rivalidad

\begin{tabular}{lcc}
\hline Elementos & Perú & Chile \\
\hline Estrategia, estructura y rivalidad local & & \\
Tiempo requerido para iniciar un negocio (días) & 72 & 27 \\
Presencia de clusters locales (PRW) & 78 & 53 \\
$\quad$ Demanda de servicios no cubiertos como porcentaje del & 12.9 & 20.0 \\
$\quad$ total de bienes y servicios exportados & & \\
\hline Estrategia, estructura y rivalidad extranjera & & 33.6 \\
Acceso a Internet por cada 100 personas & 27.4 & 7 \\
Exportaciones de alta tecnología como porcentaje del total & 2 & \\
$\quad$ de exportaciones de productos locales & 59 & 30 \\
Control internacional de la distribución (PRW) & 59 \\
\hline
\end{tabular}

Fuente: BM; FMI; IMD; WEF. 


\section{METODOLOGÍA Y RESULTADOS EMPÍRICOS}

El análisis descriptivo de la información recogida en cada variable se ha transformado en valor de ratios numéricos para mostrar el doble diamante (local y extranjero) de las economías analizadas en este estudio.

Los datos a analizar se han uniformado en scores (Cuadro 7), lo que ha permitido la elaboración de los índices para cada factor de análisis los cuales, para poder realizar su comprobación matemática, no deben pasar de 100 (Moon, Rugman, \& Verbeke, 1998, p. 145). Estos índices son los valores que se reflejan en los cuatro ejes del doble diamante de Chile y el Perú (Figuras 2 y 3 ).

Para la realización de los cálculos aritméticos se utiliza la misma metodología empleada y validada por Moon y Lee (2004, p. 12), creadores del modelo del doble diamante. Se debe mencionar que esta metodología fue empleada para evaluar la competitividad en una etapa inicial de dos economías emergentes: Singapur y Corea. Después, se aplicó a las multinacionales Samsung y Sony, básicamente para asignar un peso a cada factor en función del grado de importancia de estos con una escala menor o igual a la unidad; luego, cada peso se multiplicaba por 10 y por su peso respectivo. Así, por ejemplo (Cuadro 6), si se quiere calcular el ratio de inversión extranjera del Perú, este sería: $\left[(10)^{*}(0.25) *(3,467)\right] /(7,952)=1.09 \mathrm{y}$, para el caso de Chile, sería $\left[(10)^{*}(0.25)^{*}(7,952)\right] / 3,467=5.73$.

\section{CRITERIOS PARA INTERPRETAR EL MODELO DEL DOBLE DIAMANTE}

Moon, Rugman y Verbeke (1998) establecen algunos criterios básicos para la interpretación del modelo del doble diamante que se deben tener presentes para una adecuada comprensión de los resultados.
1) En términos generales, la economía más competitiva internacionalmente será aquella que tenga un mayor valor numérico en la sumatoria de los 4 ejes que componen el doble diamante (DD) (local y extranjero) y la base de ese éxito se encuentra soportada en el diamante, sea este local o extranjero, lo que dependerá de qué parte es mayor del diamante (la extranjera o la local) (Figura 1).

$$
\text { Donde: } \begin{aligned}
\mathrm{DD} & =\Sigma \mathrm{EER}+\mathrm{CF}+\mathrm{CD}+\mathrm{IRA} \\
\mathrm{DD} & =\text { Doble diamante } \\
\mathrm{EER} & =\text { Estrategia, estructura y rivalidad } \\
\mathrm{CF} & =\text { Condición de los factores } \\
\mathrm{CD} & =\text { Condiciones de la demanda } \\
\mathrm{IRA} & =\text { Industrias relacionadas y de apoyo }
\end{aligned}
$$

2) Si se realiza una interpretación local o internacional, aquella economía con mejor posición (local o extranjera) será la que muestre un mayor valor en la sumatoria total de los 4 ejes del diamante, por lo que se debe tener claro qué base se está tomando para el análisis.

3) En el caso del análisis individual de los 4 pilares determinantes de la competitividad de los países, aquel pilar que muestre un mejor valor en términos reales gozará de una mejor posición respecto del pilar que se tomó como referencia para comparar las economías que se analizan.

4) Si se quiere enfatizar de manera individual los factores de medida más importantes que forman los pilares sobre los que se soporta la competitividad global, la mejor economía será aquella que refleje un valor superior respecto de la economía de referencia (scores del Cuadro 7).

En las Figuras 2 y 3 se muestran los modelos del doble diamante de la economía chilena y peruana resultantes de los análisis empíricos.

Cuadro 6. Ejemplo de Cálculo de Ratios o Scores

\begin{tabular}{llllll}
\hline & & \multicolumn{2}{c}{ Valores numéricos } & \multicolumn{2}{c}{ Ratios } \\
\hline Condición de los factores extranjeros & Peso & Perú & Chile & Perú & Chile \\
\hline Inversión directa extranjera & 0.25 & 3,467 & 7,952 & 1.09 & 5.73 \\
\hline
\end{tabular}

Elaboración propia. 
Cuadro 7. Resumen y Análisis de la Data ${ }^{3}$

\begin{tabular}{|c|c|c|c|c|c|c|}
\hline Variables independientes & Fuente & Peso & Valores & Valores & Scores & Scores \\
\hline Condición de los factores locales & & & Perú & Chile & Perú & Chile \\
\hline Disponibilidad de mano de obra calificada & WEF & 0.20 & $53(131-78)$ & $97(131-34)$ & 1.09 & 3.66 \\
\hline Restricción de los flujos de capital & WEF & 0.20 & $98(131-33)$ & $67(131-64)$ & 2.92 & 1.36 \\
\hline Terrenos cultivables como porcentaje del total de área cultivable & BM & 0.40 & 16.6 & 20.4 & 3.25 & 4.91 \\
\hline Áreas forestales en 2005 (millones de km²) & BM & 0.20 & 687.4 & 161.2 & 8.52 & 0.47 \\
\hline Índice & & & & & 15.78 & 10.40 \\
\hline Condición de los factores extranjeros & & & Perú & Chile & Perú & Chile \\
\hline IDE en millones de dólares en 2006 & $\mathrm{BM}, \mathrm{FM}$ & 0.25 & 3,467 & 7,952 & 1.09 & 5.73 \\
\hline Valor agregado de la industria como porcentaje del PBI en 2006 & WEF & 0.25 & 38 & 48 & 1.98 & 3.16 \\
\hline Restricciones legales a la IDE & WEF & 0.25 & $87(131-44)$ & $115(131-16)$ & 1.89 & 3.30 \\
\hline Barreras del comercio internacional & WEF & 0.25 & $57(131-74)$ & $120(131-11)$ & 1.19 & 5.26 \\
\hline Índice & & & & & 6.15 & 17.45 \\
\hline Condición de la demanda local & & & Perú & Chile & Perú & Chile \\
\hline Tasa anual de crecimiento de la población (\%) & ONU & 0.50 & 1,1 & 1,0 & 5.50 & 4.55 \\
\hline Importación de bienes y servicios como porcentaje del PBI & BM & 0.25 & 19 & 34 & 1.40 & 4.47 \\
\hline Nivel de complejidad del mercado local & WEF & 0.25 & $67(131-64)$ & $102(131-29)$ & 1.64 & 3.81 \\
\hline Índice & & & & & 8.54 & 13.13 \\
\hline Condición de la demanda extranjera & & & Perú & Chile & Perú & Chile \\
\hline Exportación de bienes y servicios como porcentaje del PBI & BM & 0.50 & 27 & 48 & 2.81 & 8.89 \\
\hline Índice de crecimiento del mercado extranjero & WEF & 0.50 & $73(131-58)$ & $88(131-43)$ & 4.15 & 6.03 \\
\hline Índice & & & & & 6.96 & 14.92 \\
\hline Industrias relacionadas y de apoyo local & & & Perú & Chile & Perú & Chile \\
\hline Carreteras pavimentadas como porcentaje del total en 2005 & BM & 0.50 & 13,0 & 18,0 & 3.61 & 6.92 \\
\hline Disponibilidad de proveedores locales & WEF & 0.25 & $107(131-24)$ & $85(131-46)$ & 3.15 & 1.99 \\
\hline Capacidad de absorción empresarial de la tecnología & WEF & 0.25 & $39(131-92)$ & $93(131-38)$ & 1.05 & 5.96 \\
\hline Índice & & & & & 7.81 & 14.87 \\
\hline Industrias relacionadas y de apoyo extranjeras & & & Perú & Chile & Perú & Chile \\
\hline Calidad de la infraestructura del transporte aéreo & WEF & 0.33 & $33(131-98)$ & $100(131-31)$ & 1.09 & 10.00 \\
\hline Calidad de la infraestructura del transporte marítimo & WEF & 0.33 & $9(131-122)$ & $97(131-34)$ & 0.31 & 35.56 \\
\hline Disponibilidad de capital & WEF & 0.33 & $112(131-19)$ & $91(131-40)$ & 4.06 & 2.68 \\
\hline Índice & & & & & 5.46 & 48.24 \\
\hline Estrategia, estructura y rivalidad local & & & Perú & Chile & Perú & Chile \\
\hline Tiempo requerido para iniciar un negocio (días) & WEF, BM & 0.33 & $293(365-72 D)$ & $338(365-27 D)$ & 2.86 & 3.80 \\
\hline Presencia de clusters locales & WEF & 0.33 & $53(131-78)$ & $78(131-53)$ & 2.24 & 4.86 \\
\hline $\begin{array}{l}\text { Demanda de servicios no cubiertos como porcentaje de } \\
\text { bienes y servicios }\end{array}$ & BM & 0.33 & 12.9 & 20.0 & 2.13 & 5.12 \\
\hline Índice & & & & & 7.23 & 13.78 \\
\hline Estrategia, estructura y rivalidad extranjera & & & Perú & Chile & Perú & Chile \\
\hline Acceso a Internet por cada 100 personas & BM & 0.33 & 27.4 & 33.6 & 2.69 & 4.05 \\
\hline $\begin{array}{l}\text { Exportación de alta tecnología como porcentaje del total } \\
\text { de exportaciones producidas localmente }\end{array}$ & BM & 0.33 & 2.0 & 7.0 & 0.94 & 11.55 \\
\hline Control internacional de la distribución & WEF & 0.33 & $72(131-59)$ & $101(131-30)$ & 2.35 & 4.63 \\
\hline Índice & & & & & 5.98 & 20.26 \\
\hline
\end{tabular}

Fuente: BM; FMI; WEF; Organización de Naciones Unidas (ONU).

3 Los pesos descritos en el Cuadro 6 para cada variable se asignan en función del grado de importancia que ejerce como factor del doble diamante de la competitividad global. Para mayor detalle de la metodología aquí utilizada ver Moon y Lee (2004) y Moon, Rugman y Verbeke (1998). El número 131 se refiere al total de economías analizadas por el WEF para investigar la competitividad global de las naciones, por tanto, aquella que esté con una posición más cercana a la unidad es la economía que mejor calificación obtiene. 


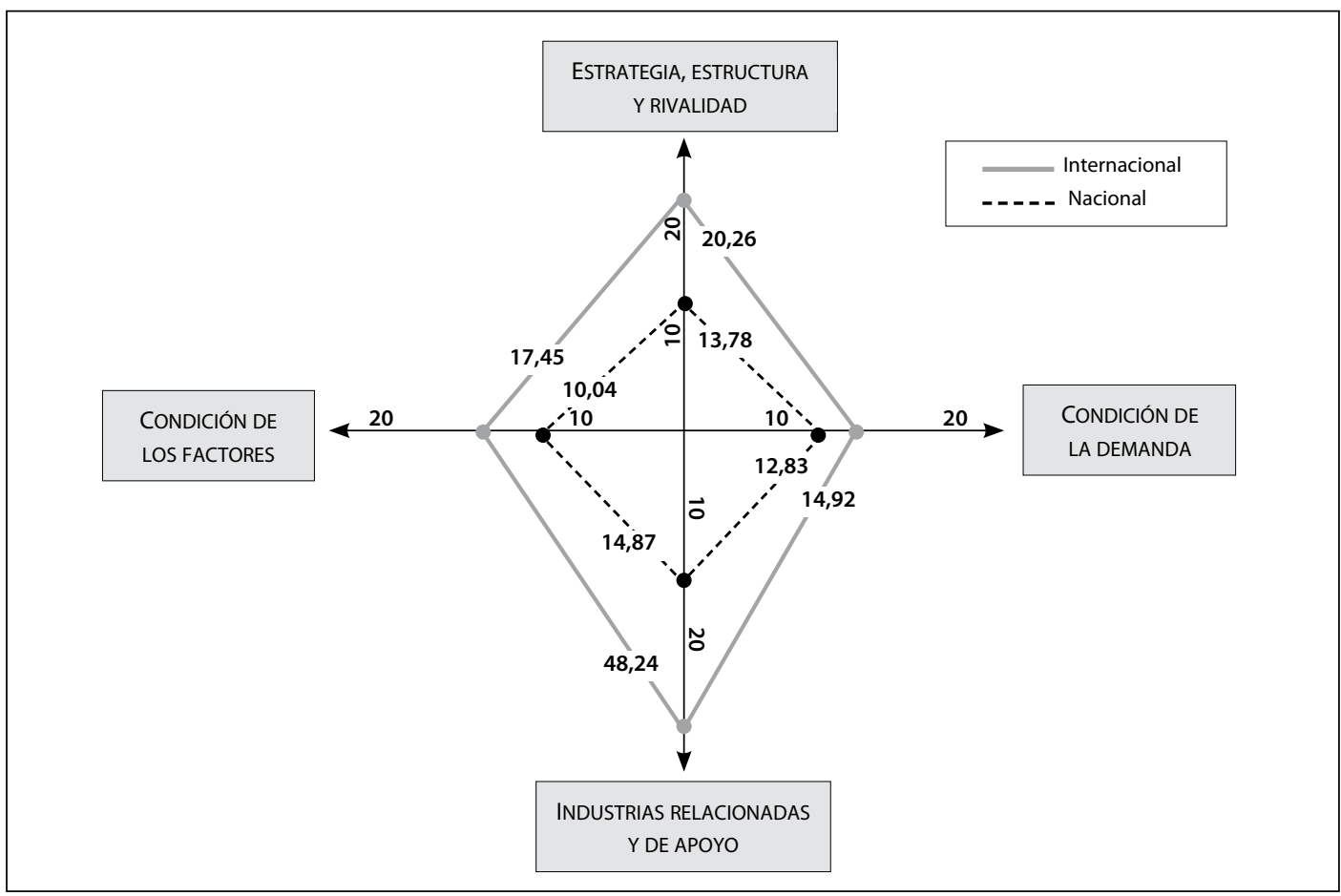

Figura 2. El doble diamante de Chile

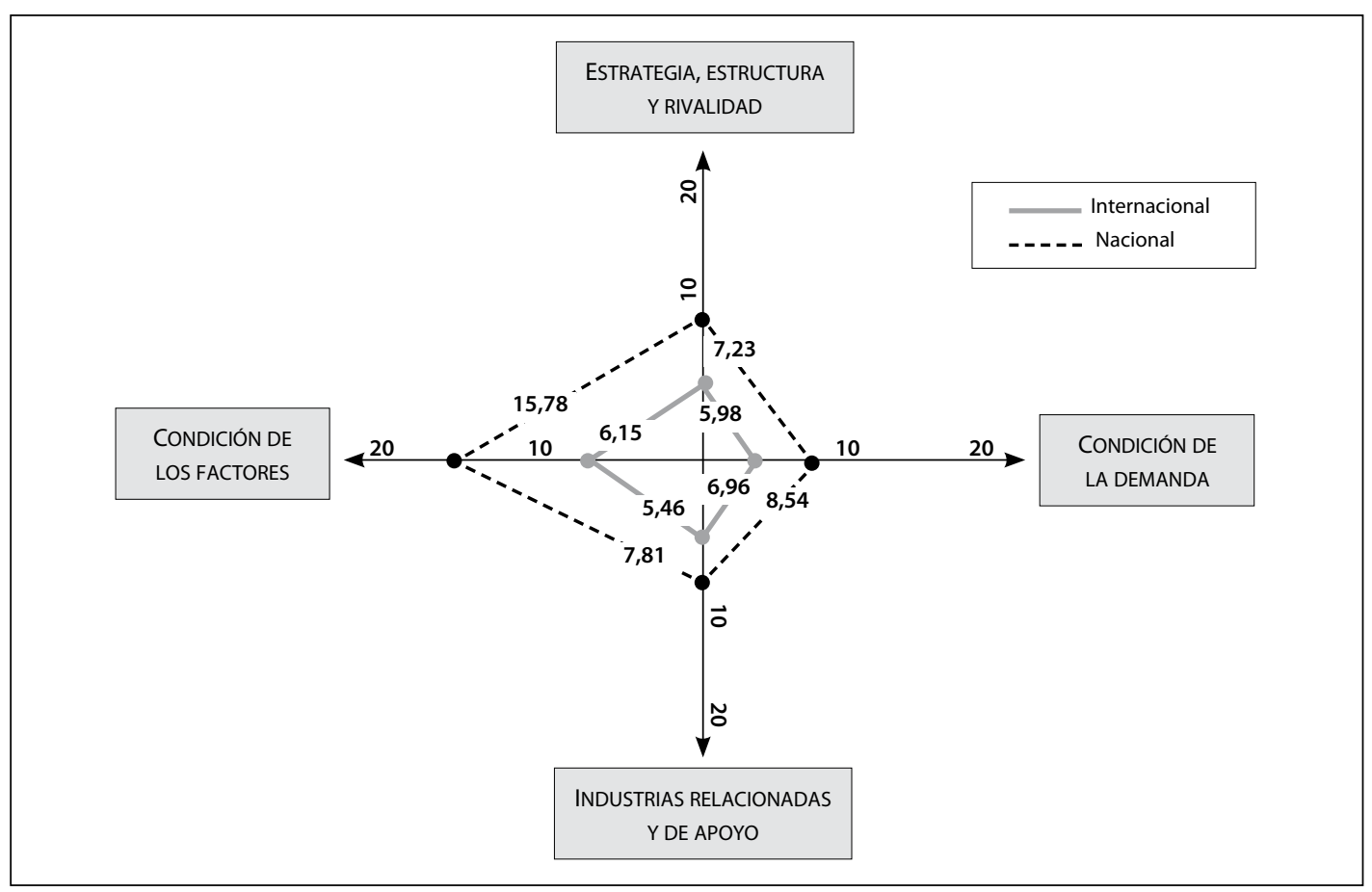

Figura 3. El doble diamante del Perú 


\section{DISCUSIÓN DEL MODELO DEL DOBLE DIAMANTE: LOS CASOS DE CHILE Y EL PERÚ}

Teniendo en cuenta la metodología descrita hasta aquí para la interpretación del modelo del doble diamante, en este acápite se procederá a su análisis.

A simple vista se puede ver que el doble diamante de Chile (Figura 2, DD Chile = local $51.88+$ extranjero 100.87) es mayor ( $D D=152.7)$ que el doble diamante de Perú (DD = 63.91) (Figura 3, DD Perú = local 39.63 + extranjero 24.55). Se puede afirmar que Chile es más competitivo que el Perú globalmente o, dicho de otro modo, que su escenario económico internacional es superior al peruano con un grado de superioridad de $41.85 \%(63.91 * 100 / 152.7)$. Esto se confirma con la posición del ránking mundial del WEF 2008 que analiza la competitividad global en el escenario económico internacional y sitúa a Chile en la posición 23 entre las 131 economías estudiadas; mientras que el Perú se ubica en la posición 86 , es decir que, según el WEF, Chile goza de una superioridad del orden de $17 \%$ (86*26/131economías) respecto del Perú.

De allí que Chile sea visto como una de las mejores economías de América Latina y, por tanto, un país más atractivo para captar la IDE, tal y como se planteaba en la introducción de este artículo.

La competitividad global superior que muestra Chile se apoya en su diamante internacional (mercado extranjero) (Figura 2, D extranjera = 100.87); mientras que el éxito de la competitividad global del Perú recae en la competitividad local (mercado local) ( $D$ local = 39.63). En ese sentido, se diría que Chile es más competitivo internacionalmente y Perú es más competitivo localmente.

En el siguiente apartado se analizan los factores que han contribuido al éxito de la competitividad.

\section{CONCLUSIONES E IMPLICACIONES PARA LA GESTIÓN}

El concepto de competitividad es un tema que está muy de moda sobre todo en economías pequeñas como las de Chile y el Perú. Este concepto representa el nuevo desafío que deben enfrentar estas economías en un mundo donde ya no se habla de mercados locales sino de mercados globales (MG). Sin embargo, el concepto de competitividad es muy complejo (Krugman, 1997, pp. 24-25; Moon, Rugman, \& Verbeke, 1998, p. 148). Por ello ha existido un gran debate entre la competitividad internacional de los países y la competitividad internacional de la empresa. No obstante, como se señaló anteriormente, hay consenso en la comunidad académica acerca de que el término competitividad puede ser usado en los tres distintos niveles: país, sector industrial yempresas.

El doble diamante resulta útil para explicar la competitividad de las economías analizadas (Perú y Chile) con el fin de determinar qué factores de las variables son los que han contribuido al éxito de esta competitividad. Al mismo tiempo, tiene implicancias tanto para los políticos como para los investigadores interesados porque permite conocer qué aspectos (factores) debe mejorar una nación si quiere ser competitiva internacionalmente.

Para analizar los factores de las 4 variables o pilares en los que se sustenta la competitividad de los países en ese sentido, y cumplir con ese propósito, se empleará el Cuadro 7 que resume los valores y sus respectivas puntuaciones en las economías en cuestión.

En lo que respecta al primer pilar (condición de los factores, locales y extranjeros), y tomando como unidad de análisis la disponibilidad de mano de obra calificada que refleja la capacidad de los países para desarrollar nuevos conocimientos, y acercarse más a las economías que se desarrollan económicamente en función de este nuevo capital valioso y escaso, se puede decir que Chile lo gestiona muy bien (Chile $=3.66$ y Perú $=1.09)$. De acuerdo con Lowe $(2003$, p. 6), este país sabe gestionar eficientemente su knowledge y lo hace igual que las naciones más desarrolladas, lo que le permite construir su ventaja competitiva extranjera (diamante extranjero) sobre uno de los factores fundamentales, el capital humano. Como diría Lowe "este país ya se mueve en función de la economía basada en el conocimiento" (knowledge based economy) (2003, p. 6). Un claro ejemplo de esta situación es la presencia 
de las universidades chilenas en los rankings mundiales (Cindoc, 2008).

Sin embargo, Chile (Chile $=0.47$ y Perú $=8.52$ ) tiene una evaluación muy baja en lo que respecta a la conservación y la protección de sus recursos naturales medida a través de la cantidad de áreas forestales con las que cuenta el país sobre el total de áreas naturales; en este sentido se puede afirmar que, de acuerdo con las exigencias del nuevo orden económico internacional (WEF, 2008), se demanda que los países tengan más en cuenta la ecología, puesto que en la actualidad la conservación del planeta se considera responsabilidad de todos. En este factor, el Perú tiene una calificación envidiable respecto de Chile, lo que significa que se encuentra mejor enmarcado que Chile en el nuevo orden económico internacional.

Respecto del papel que cumplen las IDE en la competitividad de los países, se puede ver claramente que el Perú, según el Cuadro 6, tiene poca capacidad para atraerlas, puesto que muestra una tasa deficitaria de $43 \%$ respecto de Chile (Perú 3,467/Chile $7,952 * 100=43$ ), quizás una de las razones sea la estabilidad macroeconómica que deben mostrar los países para ser más atractivos para las IDE. El informe WEF (2008, pp. 132 y 274) sitúa al Perú en la posición 67 , lo que es signo de poca estabilidad macroeconómica, mientras que Chile está entre los 14 primeros países con mayor estabilidad macroeconómica. De allí que las IDE se dirijan más y en mayor cantidad a Chile que al Perú. Por tanto, en este tema de manera muy particular la labor del gobierno vuelve a desempeñar un papel importantísimo al ser este uno de los principales promotores de la búsqueda de dichas inversiones en los MG.

En lo relacionado con el segundo pilar determinante de la competitividad de los países (condiciones de la demanda), la importación de bienes y servicios evalúa la capacidad que tienen las industrias locales de un país para rivalizar con competidores extranjeros, lo que permite la preparación de las empresas nacionales para salir a competir a los mercados extranjeros en forma eficiente. Nuevamente Chile muestra un nivel superior (Chile $=4.7$ y Perú $=1.40$ ), lo que se confirma con el ratio obtenido en exporta- ciones, donde Chile tiene mayor volumen (Chile $=8.9$ y Perú $=2.81$ ), de lo que se desprende que las industrias chilenas están mejor preparadas para rivalizar en los mercados extranjeros. De allí que, de acuerdo con el análisis del doble diamante, en una escala global Chile pueda ser considerado un mejor escenario económico para invertir.

Junto a las condiciones de la demanda se encuentra el tercer pilar que ayuda a la configuración de un mejor escenario económico o una mayor competitividad internacional de los países (industrias relacionadas y de apoyo). Aquí, las industrias locales para lograr un alto grado de desarrollo económico internacional, tal y como hacen aquellas de los países altamente industrializados, necesitan de un alto nivel de desarrollo de la infraestructura física (Chen \& Lim, 2006), como carreteras y aeropuertos; alto desarrollo tecnológico; presencia de proveedores locales; etcétera. No se puede afirmar que la economía chilena tenga un nivel superior en todos los factores de medida de esta variable, pero sí se puede rescatar que Chile, por ejemplo, tiene valores menores en el factor referido a la disponibilidad de proveedores locales (Perú $=3.15$ y Chile $=1.99$ ). Por otro lado, se debe destacar que los empresarios en el Perú disponen de mayor capital (Perú $=4.6$ y Chile $=$ 2.68), de acuerdo con el WEF (2008).

En cuanto al cuarto pilar determinante de la competitividad global de los países (estrategia, estructura y rivalidad), si se considera el factor tiempo para iniciar un negocio se puede decir que en Chile es posible abrir un negocio en menor tiempo, mientras que en el Perú un empresario tarda más tiempo con una tasa diferencial de $166 \%$ ( $72-27=45 \rightarrow 45^{*} 100 / 27$ $=166$ ), lo que significa que en el Perú existe una excesiva burocracia administrativa, por lo que se sugiere la informatización de los procesos administrativos. El uso de nuevas tecnologías se mide mediante el número de personas con acceso a Internet por cada cien habitantes $y$, en el plano industrial, se considera el nivel de informatización de un país el cual permite que las empresas ofrezcan sus productos o servicios a los mercados extranjeros (Chile 34 por cada cien y el Perú, 27). Por tanto, la industria chilena tiene mayores posibilidades de ofrecer sus productos en los mercados extranjeros. 
Pero el nivel de informatización no solo es favorable para las industrias locales, sino también es bueno para la educación puesto que mejora su calidad (WEF, 2008) al permitir que los ciudadanos accedan a los conocimientos que se desarrollan en terceros países y, además, intercambian conocimientos, lo que enriquece la educación de las personas en los niveles básico y universitario. Por tanto, se sugiere que el gobierno del Perú invierta en un mayor nivel de informatización, con lo que conseguirá no solo mejorar la educación sino también permitir que las empresas, sobre todo las pequeñas, puedan dar a conocer sus productos en los MG.

Las exportaciones de alta tecnología son menores en el Perú con una tasa diferencial de $28 \%(2.0 * 100 / 7)$, lo que significa que el desarrollo tecnológico en el Perú es bajo. Como se indica en la literatura analizada, el nivel de desarrollo tecnológico de un país no es solo responsabilidad de la industria sino que también lo es de universidades y centros de investigación local, los cuales generan desarrollo tecnológico (Nilsson, Arbo, Dahl, Dahlum, Edvardsson, Eskelinen, Nielsen, Uhlin, \& Linenpää, 2005). Un claro ejemplo lo constituyen Estados Unidos y los países asiáticos en los cuales este desarrollo tecnológico se explica por el papel que cumplen las universidades y los centros de investigación y también, actualmente, en algunos países de Europa del Este (Nilsson et ál., 2005).

DE ACUERDO CON EL MODELO de desarrollo económico internacional flying geese (Kojima, 2003), el Perú podría alcanzar la competitividad global que ha obtenido Chile (Figura 2). Sobre este enfoque se puede decir que el Perú y Chile pertenecen a la misma familia de "gansos", pues son de la misma región económica y tienen iguales recursos físicos, en otras palabras, tiene las mismas "alas" para poder volar bastante y alto internacionalmente. No obstante, el Perú deberá mejorar en aquellos factores del modelo en los que registra niveles inferiores (ver Cuadro 7) respecto de Chile.

Con este modelo de competitividad global se ha podido demostrar que Chile es más competitivo que el Perú globalmente, puesto que tiene un doble diamante (local y extranjero) superior que el Perú con una tasa diferencial de $42 \%$. Resumiendo, al Perú le queda mucho camino por recorrer si quiere ser tan competitivo globalmente como lo es Chile.

La gran mayoría de implicaciones para la gestión prácticamente ya se han indicado anteriormente, o están implícitas, sin embargo, vale la pena plantear dos cuestiones claves que podrían ayudar a mejorar la competitividad internacional de la economía peruana:

1) Elevar el nivel de inversión destinado a la educación en general, puesto que en un futuro no muy lejano los países comenzarán a competir en función del conocimiento, y si un país no cuenta con una educación adecuada para elaborar este nuevo capital difícilmente llegará a estar en la liga de las grandes economías mundiales. Sin embargo, el Instituto Nacional de Estadística e Informática del Perú (INEI, 2009) afirma que en los últimos años los gastos destinados a inversión en educación han caído respecto de años anteriores, lo que también se confirma con los análisis realizados por el IMD (2008) y el WEF (2008) que sitúan al Perú en una posición inferior en cuanto a la inversión en educación.

2) Por otro lado, respecto de la captación de IDE en los mercados extranjeros, el Perú debería seguir el ejemplo de las mejores economías, es decir, hacer benchmarking. Para ello debería tener agentes comerciales, como los tiene cualquier empresa que quiere ofrecer un producto en el exterior, pero estos agentes han de tener las competencias necesarias (economics \& business) para que puedan promocionar al país de manera adecuada, puesto que un país con ingresos bajos no puede darse el lujo de tener burócratas en el extranjero. Como ejemplo se puede citar a España que tiene agentes de promoción de IDE desplegados por todos los rincones del mundo, quienes promocionan al país a través de reuniones, tertulias, cenas con empresarios, conferencias y cátedras, entre otras actividades.

O algunos países de la región andina las cuales se amparan básicamente bajo el paraguas de algunas universidades estadounidenses que imparten asignaturas vinculadas a los mercados de la región (como “Doing business with Latin America”), detrás de ellas se encuentra la búsqueda de inversión 
extranjera de algunas multinacionales y gobiernos de la región que patrocinan activamente este tipo de asignaturas en las escuelas de economía y negocios.

\section{LIMITACIONES Y FUTURAS INVESTIGACIONES}

Una de las limitaciones que muestra el modelo del doble diamante es que centra su atención en el análisis del sector industrial y descuida así el valor que puede generar el sector servicios para una economía, y quizá no pudiera ser aplicado a economías o regiones donde el crecimiento económico se basa en el sector servicios. Como futura línea de investigación se propone realizar un análisis comparativo utilizando la misma metodología con otra economía de Hispanoamérica como Brasil o México. Asimismo, aplicar este modelo a las regiones del Perú para determinar cuál sería la región más competitiva del Perú en términos globales.

\section{REFERENCIAS}

Acedo, F. J., Barroso, C., \& Galán, J. L. (2006). The resource-based theory: Dissemination and main trends. Strategic Management Journal, 27, 621-636.

Arze, E. C., \& Svensson, B. (1997). Development of international competitiveness in industries and individual firms in developing countries: The case of the Chilean forest-based industry and the Chilean engineering firm Arze, Recin y Asociados. International Journal of Production Economics, 52, 185-202.

Banco Interamericano de Desarrollo (BID). (2008). Indicadores económicos, financieros y sociales sobre los países de América Latina y El Caribe. Recuperado el 28 de setiembre de 2008 en <http://www.iadb.org>.

Banco Mundial. (2008). Estadísticas e indicadores. Recuperado el 28 de setiembre de 2008 en <www.bancomundial. org>.

Belso-Martínez, J. A. (2006). Why are some Spanish manufacturing firms internationalizing rapidly? The role of business, and institutional international networks. Entrepreneurship \& Regional Development, 18(3), 207226.

Casillas, J. C. (2001). Introducción a la administración internacional. Sevilla: Edición digital @tres S. L. L.

Centro de Documentación e Información Científica (Cindoc). (2008). Ranking Web de Universidades: Top Latinoamérica. Recuperado el 28 julio de 2008 en <http://www. webometrics.com>.

Conferencia de las Naciones Unidas sobre Comercio y Desarrollo (Unctad). (2008). Estadísticas de la Unctad. Recuperado el 28 setiembre de 2008 en <www.unctad. org>.
Chen, Y. M., \& Lin, F. J. (2006). Regional development and sources of superior performance across textile and IT sectors in Taiwan. Entrepreneurship and Regional Development, 18(3), 227-248.

Cho, D. S. (1994). Dynamic approach to international competitiveness: The case of Korea. Journal of Far Eastern Business, 1(1), 17-36.

Cho, D. S., \& Moon, H. C. ([1998] 2000). From Adam Smith to Michael Porter, evolution of competitiveness theory. Singapur: World Scientific Publishing.

Cho, D. S., Moon, H. C., \& Kim, M. I. (2007). Characterizing international competitiveness in international business research: A MASI road to national competitiveness. Research in International Business and Finance, 22(2), 175-192.

Cho, D. S., Moon, H. C., \& Kim, M. I. (2009). Does one size fit all? A dual double diamond a road to country-specific advantages. Asian Business \& Management, 8, 83-102.

Choo, C. H. J. (1999). Global competitiveness and national attractiveness. International Studies of Management \& Organization, 29(1), 3-13.

D'Cruz, J. R., \& Rugman, A. M. (1993). Developing international competitiveness: The five partners. Business Quarterly, 58(2), 61-73.

Del Sol, P., \& Kogan, J. (2007). Regional competitive advantage based on pioneering economic reforms: The case of Chilean FDI. Journal of International Business Studies, 38, 901-927.

Drucker, P. (2003). La empresa en la sociedad que se viene. Barcelona, España: Urano. 
Dunning, J. H., \& Lundan, S. M. (1998). The geographical sources of competitiveness of multinational enterprises: An econometric analysis. International Business Review, 7, 115-133.

Fahy, J. A. (2002). Resource-based analysis of sustainable competitive advantage in a global environment. International Business Review, 11, 57-78.

Fondo Monetario Internacional (FMI). (2008). Data and statistics, world economic outlook database. Recuperado el 28 de setiembre de 2008 en <www.imf.org >

Galán, J. I., González-Benito, J., \& Zúñiga-Vincente, J. A. (2007). Factors determining the location decisions of Spanish MNEs: An analysis based on the investment development path. Journal of International Business Studies, 38, 975-997.

Garrido-Lecca, H. (2008, octubre). Concentración bancaria en el Perú, 1997-2006. Tesis doctoral no publicada, Universidad de Sevilla.

Grant, R. M. (1991). Contemporary strategy analysis: Concepts, techniques, applications. Cambridge: Basil Blackwell.

Heckscher, E. F. ([1919] 1949). The effect of foreign trade on the distribution of income. En S. E. Howard \& A. Lloyd A. Metzler (Eds.). Readings in the theory of international trade (272-300). Homewood, Il: Irwin.

Hume, D. ([1752] 1999). Resumen del tratado de la naturaleza humana. Mataró, España: El Viejo Topo.

Hymer, S. H. ([1960] 1976). The international operations of national firms: A study of direct foreign investment. Cambridge: MIT Press.

Institute for Management and Development (IMD). (2008). The IMD World Competitiveness Yearbook. Recuperado el 28 septiembre de 2008 en <www.imd.ch>.

Instituto Español de Comercio Exterior (ICEX). (2008). Estudios de mercado y otros documentos. Recuperado el 28 setiembre de 2008 en <www.icex.es $>$.

Jin, B., \& Moon, H. C. (2006). The diamond approach to the competitiveness of Korea's apparel industry Michael Porter and beyond. Journal of Fashion Marketing and Management, 10(2), 195-208.

Kasahara, S. (2004). The flying geese paradigm: A critical study of its application to East Asian regional development. Unctad Discussion Papers N. 169. Ginebra / Nueva York, NY: Unctad.
Kojima, K. (2003). Gankogata keizai hattenron. The flyinggeese theory of economic development. Tokio, Japan: Bunshindo.

Krugman, P. (1997). El internacionalismo moderno: la economía internacional y las mentiras de la competitividad. Barcelona, España: Crítica / Grijalbo.

Leontief, W. W. (1953). Domestic production and foreign trade: The American position reexamined. Proceedings of the American Philosophical Society, 97, 332-349. (Reimpresión: (1966). Input-Output Economics. Nueva York: Oxford University Press.

Lora, E. (2005). ¿Debe América Latina temerle a la China? (Research Department Working Paper). Washington, D.C.: Cataloging-in-Publication data provided by the InterAmerican Development Bank (IDB).

Lowe, G. (2003, 19 de mayo). The quality of work features prominently in Europe's plan for competitiveness. Canadian HR Reporter.

Moon, H. Ch., \& Lee, D. (2004). The competitiveness of multinational firms: A case study of Samsung Electronic and Sony. Journal of International and Area Studies, $11(1), 1-21$.

Moon, H. Ch, Rugman, A. M., \& Verbeke, A. (1995). The generalized double diamond approach to international competitiveness. En A. M. Rugman (Ed.). Research in global strategic management: A Research Annual, 5, 97-114.

Moon, H. Ch., Rugman, A. M., \& Verbeke, A. (1998). The generalized double diamond approach to international competitiveness of Korea and Singapore. International Business Review, 7, 135-150.

Nilsson, J. E., Arbo, P., Dahl, M. S., Dahlum, B., Edvardsson, I. R.,

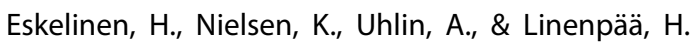
(2005). The role of universities in regional innovation systems - A Nordic perspective. Jan-Evert Nilsson (Ed.). Copenhague, Dinamarca: CBS Press.

Ohlin, B. ([1933] 1948). Interregional and international trade. Madrid, España: Aguilar.

Organización de Naciones Unidas (2008). Recuperado el 28 setiembre de 2008 en <www.un.org/spanish >.

Parker, P. M. (2006a). Chile economic competitiveness. En ABI Global Inform. San Diego, CA: Insead (Institut Européen d'Administration des Affaires). 
Parker, P. M. (2006b). Peru economic competitiveness. En $A B I$ Global Inform. San Diego, CA: Insead.

Peña-Vinces, J. C. (2008, 15 de agosto). La competitividad internacional en el mundo actual. Conferencia internacional, Facultad de Ciencias Administrativas. Lima, Perú: Universidad Nacional Mayor de San Marcos.

Perú. Instituto Nacional de Estadística e Informática (INEI). (2009). Inversión en educación debe incrementarse anualmente en $0.25 \%$ del PBI. Recuperado el 20 de mayo de 2009 en <http://iinei.inei.gob.pe>.

Porter, M. E. (1990). The competitive advantage of nations. Nueva York: The Free Press.

Porter, M. E. (1991). The Monitor Company Canada at the crossroads: The reality of a new competitive environment. Ottawa: Business Council on National Issues and Minister of Supply and Services of the Government of Canada.

Porter, M. E. (1998). On competition. Boston: Harvard Business School.

Porter, M. E. (2007). Entrevista en el WEF. Recuperado el 28 de setiembre del 2008 en <www.wef.com>.

Porter, M. E., Delgado, M., Ketels, K., \& Stern, S. (2008). Moving to a new global competitiveness Index (Capítulo 1.2, 43-63). The Global Competitiveness Index: World Economic Forum. Ginebra / Nueva York: WEF.

Ricardo, D. C. ([1817] 1971). The principles of political economy and taxation. Baltimore: Penguin.

Rugman, A. M., \& D'Cruz, J. R. (1993). The double diamond model of international competitiveness: Canada's experience. Management International Review, 33(2), 17-39.

Sala-I-Martin, X., Blanke, J., Drzeniek Hanouz, M., Geiger, T., Mia, I., \& Paua, F. (2008). Prioritizing the economic policy agenda (Capítulo 1.1, 3-41). The Global Competitiveness Index: World Economic Forum. Ginebra / Nueva York: WEF.

Salas, V. (1999). Empresa y competitividad. Economía Aragonesa. Zaragoza, España: Ibercaja, Plaza de Basilio Paraíso.

Smith, A. ([1776] 1937). An inquiry into the nature and causes of the wealth of nations. Charles W. Eliot (Ed.). Nueva York: P. F. Collier \& Son.

Solleiro, J. L., \& Castañón, R. (1995). Competitividad y sistemas de innovación: los retos para la inserción de México en el contexto global. En Temas de lberoamérica Globalización, Ciencia y Tecnología. México, D. F.: Dirección General de Asuntos del Personal Académico (DGAPA), Universidad Nacional Autónoma de México, pp. 165-197.

Vernon, R. ([1966] 1979). The product cycle hypothesis in a new international environment. Oxford Bulletin of Economics and Statistics, 41, 255-267.

Villarreal, R., \& Villarreal, R. (2002). México competitivo al 2020. México, D. F., México: Plaza y Valdés.

World Economic Forum (2008). The Global Competitiveness Report 2007-2008. Recuperado el 28 setiembre de 2008 en <http://www.weforum.org >. 
